\title{
O REGIME DAS AUTORIZAÇÕES AMBIENTAIS NO BRASIL: BREVES NOTAS SOBRE A NOVEL REGULAMENTAÇÃO
}

\author{
LEONARDO LUIZ SELBACH \\ Universidade do Vale do Itajaí / Universidad de Alicante \\ selba@hotmail.com
}

Recebido: 23 de março de 2012 / Aceito: 22 de maio de 2010

RESUMO: Investigou-se, com a devida brevidade, a novel regulamentação do procedimento geral das autorizações ambientais no Brasil, afirmando que deve ser observada a unicidade de licenciamento, pois a lei complementar inovando a sistemática anterior expressamente balizou limites ao princípio da supletividade, bem como trouxe regramento quanto a observâncias de prazos.

RESUM: S'investiga, amb la brevetat deguda, les noves normes generals dels permisos ambientals al Brasil. Es defensa, en aquest context, que cal tenir en compte la singularitat de la concessió de llicències, ja que la nova llei pretén modificar el sistema anterior, particularmente en relació amb l'estructura i la fixació de límits expressos al principi de supletorietat. A més, també cal tenir en compte les mesures relatives a l'observança dels terminis.

RESUMEN: Se investiga, con la brevedad debida, las normas generales de los permisos ambietnales en Brasil. Se defiende, en este contexto, que debe tenerse en cuenta la singularidad de la concesión de licencias, ya que la nueva ley pretende modificar el sistema anterior, particularmente en relación con la estructura y la fijación de límites expresos al principio de supletoriedad. Además, también debe tenerse en cuenta las medidas relativas a la observancia de los plazos. 
ABSTRACT: This paper aims to fix, with due brevity, the new general rules of environmental permits in Brazil. The author states that it should be noted the uniqueness of licensing, because the new regulation makes innovations in the previous system, adding structure and establishing limits to the principle of additionality, as well as bringing a method to order the observances of deadlines.

PALAVRAS-CHAVE: Licenciamento — proteção do Meio Ambiente — prazo Regulamentação

PARAULES CLAU: Llicències — protección del medi ambient — terminis regulació

PALABRAS CLAVE: Licencias — protección del medi ambiente — plazos — regulación

KEYWORDS: Permits - environmental protection - terms — regulation

Sumario: I. Do regime das autorizações ambientais no Brasil. 1. Notas Introdutórias. 2. Do Instrumento da Política Nacional do Meio Ambiente. 3. Da Unicidade de Licenciamento Ambiental. 4. Do Procedimento Administrativo Público. II. Considerações finais. III. Referências.

\section{DO REGIME DAS AUTORIZAÇÕES AMBIENTAIS NO BRASIL}

\section{Notas Introdutórias}

O direito brasileiro pode-se dizer verdadeiramente positivado, pois tem sofrido ao longo dos anos uma verdadeira enxurrada legislativa, ao ponto do presidente do Senado José Sarney ${ }^{1}$ aduzir que "há no Brasil é um excesso de legislação. Temos aqui milhares e milhares de leis que tornam tudo quase impossível. E aí gosto de citar Montesquieu, que dizia que muitas leis, nenhuma lei. É o que acontece um pouco no Brasil, argumentou".

\footnotetext{
${ }^{1}$ Baptista, Rodrigo. Sarney critica excesso de leis no Brasil. Agência Senado, Brasília, 01 dez. 2010. Notícias. Disponível em: <http://www.senado.gov.br/noticias/sarney-critica-excesso-de-leis-nobrasil.aspx>. Acesso em: 01 fev. 2012.
} 
Devido a grande gama de legislação o direito brasileiro está se tornando complexo e o estudo das competências está ganhando cada vez mais importância, competência esta que no âmbito de direito ambiental, de acordo com José Afonso da Silva ${ }^{2}$, pode ser conceituada como "as diversas modalidades de poder que se servem os órgãos ou entidades estatais para realizar suas funções, suas tarefas, prestar serviços”.

Note-se que a organização do Estado Brasileiro também é intricada, mas para fins do Direito Ambiental Brasileiro material a Carta Magna os referiu e os disciplinou no art. 23:

"É competência comum da União, dos Estados, do Distrito Federal e dos Municípios:

III - proteger os documentos, as obras e outros bens de valor histórico, artístico e cultural, os monumentos, as paisagens naturais notáveis e os sítios arqueológicos;

VI - proteger o meio ambiente e combater a poluição em qualquer das formas;

VII - preservar as florestas, fauna e flora;

$(\ldots)$

Parágrafo único. Leis complementares fixarão normas para a cooperação entre a União e os Estados, o Distrito Federal e os Municípios, tendo em vista o equilíbrio do desenvolvimento e do bem-estar em âmbito nacional [Redação dada pela Emenda Constitucional n ${ }^{\circ} 53$, de 2006]".

Trata-se, in casu, de uma competência material comum da União, dos Estados, do Distrito Federal e dos Municípios, e diz respeito à prestação dos serviços referentes às matérias de alguns incisos do art. 23 da CF que trazem à baila à proteção do meio ambiente cultural ou natural, à tomada de providências para a sua realização, por exemplo.

$\mathrm{O}$ art. 23, em seu parágrafo único, da Constituição Federal afirma que haverá lei complementar disciplinando a cooperação entre os entres federados regulamentando a competência material comum, ou seja, aquela que permite aos entes fiscalizar, implementar e licenciar questões ambientais.

\footnotetext{
${ }^{2}$ SILVA, José Afonso. Direito ambiental constitucional. 6 ed. São Paulo: Malheiros, 2007. p. 72.
} 
Obtempera-se que a inovação legislativa do poder constituinte derivado ocorreu em 2006 e somente em 2011 entra em vigor a novel Lei Complementar n. 140 de 08 de dezembro de 2011, com o fito de fixar normas para a cooperação entre os entes federativos, conforme dispõe seu artigo $1^{\mathrm{o}}$ :

"Esta Lei Complementar fixa normas, nos termos dos incisos III, VI e VII do caput e do parágrafo único do art. 23 da Constituição Federal, para a cooperação entre a União, os Estados, o Distrito Federal e os Municípios nas ações administrativas decorrentes do exercício da competência comum relativas à proteção das paisagens naturais notáveis, à proteção do meio ambiente, ao combate à poluição em qualquer de suas formas e à preservação das florestas, da fauna e da flora".

Poder-se-ia, equivocadamente, afirmar, então, que somente em 2011 houve a regulamentação da competência comum ambiental e a cooperação dos entes federativos nas questões ambientais.

Ocorre que a proteção ambiental já estava sendo garantida pela lei 6.938/81, que trata da Política Nacional do Meio Ambiente, que prevê, ainda, no seu art. $8^{\circ}$ :

"Compete ${ }^{3}$ ao CONAMA ${ }^{4}$ :

I - estabelecer, mediante proposta do $\mathrm{IBAMA}^{5}$, normas e critérios para o

licenciamento de atividades efetiva ou potencialmente poluídoras, a ser concedido pelos Estados e supervisionado pelo IBAMA" ${ }^{\prime 6}$.

A norma paradigmática a que este artigo se refere é a Resolução $n^{\circ}$ 237/97 do Conselho Nacional do Meio Ambiente (CONAMA) ${ }^{7}$. Vê-se, então, que já havia uma sistemática regulamentar ambiental, em que o operador jurídico deveria se imiscuir no sistema protetivo ambiental, conhecendo as resoluções do CONAMA, inclusive.

Cite-se, por oportuno, o art. $1^{\circ}$, I, da referida Resolução que conceitua:

"Licenciamento Ambiental: procedimento administrativo pelo qual o órgão ambiental competente licencia a localização, instalação, ampliação e a operação de

\footnotetext{
${ }^{3}$ Redação do art. $8^{\circ}$, caput, alterada pela Lei n ${ }^{\circ} 8.028$, de 1990.

${ }^{4}$ Conselho Nacional do Meio Ambiente (instituído pela Lei n. 6.938, de 31 de agosto de 1981).

${ }^{5}$ Instituto Brasileiro do Meio Ambiente e Recursos Naturais Renováveis (criado pela Lei n. 7.735, de 22 de fevereiro de 1989).

${ }^{6}$ Redação do art. $8^{\circ}$, inciso I, alterada pela Lei $n^{\circ} 7.804$, de 1989 . O grifo é nosso.

7 BRASIL. Conselho Nacional do Meio Ambiente. Resolução 237 de 19 de dezembro de 1997. Disponível em <www.mma.gov.br>. Acesso em 24 nov 2011.
} 
empreendimentos e atividades utilizadoras de recursos ambientais, consideradas efetiva ou potencialmente poluidoras ou daquelas que, sob qualquer forma, possam causar degradação ambiental, considerando as disposições legais e regulamentares e as normas técnicas aplicáveis ao caso".

Transcreve-se, para comparação, o art. $2^{\circ}$, I, da Lei Complementar n. 140/2011:

"licenciamento ambiental: o procedimento administrativo destinado a licenciar atividades ou empreendimentos utilizadores de recursos ambientais, efetiva ou potencialmente poluidores ou capazes, sob qualquer forma, de causar degradação ambiental".

A ulterior norma trouxe conceito mais generalizante, mas com contornos similares, isto é, não houve modificação substancial, nem superou a celeuma do termo licenciamento ambiental não traduzir a expressão jurídica licença, com o devido rigor técnico ${ }^{8}$, empregando-a de forma promiscua ${ }^{9}$.

Não se está dizendo que o termo licenciamento ambiental esteja de todo equivocado, mas sim que está empregado de forma não técnica e ampla para os diversos casos, que se dá a falsa ideia de que ela possa ser entendida como uma licença de Direito Administrativo ${ }^{10}$.

Licença para o Direito Administrativo, seguindo o entendimento de Dirley da Cunha Júnior $^{11}$ :

"É ato administrativo unilateral, vinculado e definitivo através do qual a Administração Pública reconhece, em benefício do administrado, um direito relativamente ao exercício de uma atividade jurídica (ex.: atividade profissional dependente de licença da OAB, CREMEB, CREA, ETC) ou material (ex.: licença para construir, de localização e funcionamento, etc)".

De outra banda, a autorização ${ }^{12}$ é:

“(...) ato precário e discricionário, porque não pressupõe um direito anterior a ser exercido. Vale dizer, o direito ao exercício da atividade autorizada nasce com a

\footnotetext{
${ }^{8}$ MACHADO, Paulo Affonso Leme. Direito ambiental brasileiro. 12 ed. São Paulo: Malheiros, 2004. p. 257.

${ }^{9}$ SILVA, José Afonso. Direito ambiental constitucional cit.. p. 280.

${ }^{10}$ ANTUNES, Paulo de Bessa. Direito ambiental. 8 ed. Rio de Janeiro: Lumen Juris, 2005. p. 107.

${ }^{11}$ CUNHA JÚNIOR, Dirley da. Curso de direito administrativo. 7 ed. $2^{\mathrm{a}}$ tirag. Salvador: Editora Juspodivm, 2008. p. 120.

${ }^{12}$ SILVA, José Afonso. Direito ambiental constitucional cit.. p. 280.
} 
outorga da autorização. Ao contrário, ela pressupõe uma proibição geral, expressa ou decorrente do sistema, ao exercício da atividade. Sua outorga consiste, assim, em remover esse obstáculo em favor de alguém, por razões de conveniência ou de mera liberalidade da Administração".

Podendo-se, então, aduzir que quando a Lei 6.938/81, a Lei Complementar 140/2011 e o art. 225, caput, da Constituição Federal citam o termo licenciamento este deve ser entendido como sinônimo de autorização ${ }^{13}$, motivo pelo qual estamos tratando do regime das autorizações ambientais, mas fazemos referência a licença e licenciamento ambiental.

\section{Do Instrumento da Política Nacional do Meio Ambiente}

Relevante apontar que as autorizações ambientais é um dos instrumentos da política nacional do meio ambiente do Brasil, constantes no art. $9^{\circ}$, da Lei 6.938/81, ao lado do zoneamento ambiental, do sistema nacional de informações sobre o meio ambiente e de instrumentos econômicos, como concessão florestal, servidão ambiental, seguro ambiental e outros.

As referidas autorizações são a manifestação do controle administrativo preventivo ambiental, decorrente do poder de polícia do Estado, sendo exigível, em regra ${ }^{14}$, das obras e atividades potencialmente causadoras de significativa degradação do meio ambiente, por expressa disposição constitucional, prevista no art. $225, \S 1^{\circ}$, IV, verbis: “exigir, na forma da lei, para instalação de obra ou atividade potencialmente causadora de significativa degradação do meio ambiente, estudo prévio de impacto ambiental ${ }^{15}$, a que se dará publicidade".

\footnotetext{
${ }^{13}$ MUKAI, Toshio. Direito ambiental sistematizado. 5 ed. Rio de Janeiro: Forense Universitária, 2005. p. 90 .

${ }^{14}$ Cita-se, a propósito: "Primeiramente, cumpre esclarecer que o EIA/RIMA nem sempre é obrigatório, porquanto o próprio Texto Constitucional condiciona a existência desse instrumento às obras e atividades potencialmente causadoras de significativa degradação ambiental (art. $225, \S 1^{\circ}$, IV), e nem toda atividade econômica possui essa característica". FIORILLO, Celso Antônio Pacheco. Curso de direito ambiental brasileiro. 9 ed. São Paulo: Saraiva, 2008. p. 93.

${ }^{15}$ Colaciona-se, a propósito: "Logo se percebe a extrema vagueza do conceito legal. Mas nem poderia ser de outra forma, pois o Texto Constitucional não admitiria a exclusão de obras que fossem promotoras, ainda que potencialmente, de degradação do ambiente, da elaboração prévia de estudo de impacto ambiental". BASTOS, Celso Ribeiro. Curso de direito constitucional. 22 ed. São Paulo: Malheiros, 2010. p. 682.
} 
Note-se que a exigência é constitucional não podendo os Estados-membros desobrigarem determinadas obras ou atividades, in abstrato, nem mesmo por previsão constitucional Estadual. O fato, em questão, já foi objeto de análise pelo Supremo Tribunal Federal, na Ação Direta de Inconstitucionalidade n. 1.086, Rel. Min. Ilmar Galvão, julgada em 07-06-2001:
"Ação direta de inconstitucionalidade. Art. 182, § 3º da Constituição do Estado de Santa Catarina. Estudo de impacto ambiental. Contrariedade ao art. 225, § $1^{\circ}$, IV, da Carta da República. A norma impugnada, ao dispensar a elaboração de estudo prévio de impacto ambiental no caso de áreas de florestamento ou reflorestamento para fins empresariais, cria exceção incompatível com o disposto no mencionado inciso IV do $§ 1^{\circ}$ do art. 225 da CF",16.

De se ver, então, que a outorga da licença, por vezes, é condicionada a realização de algum tipo de estudo ambiental, como o Relatório Ambiental, Plano e Projeto de Controle Ambiental, Relatório Ambiental Preliminar, Diagnóstico Ambiental, Plano de Manejo, Plano de Recuperação de Área ${ }^{17}$.

Transcreve-se, clarificando a aplicação desses estudos prévios, as palavras de Celso Antônio Pacheco Fiorillo ${ }^{18}$ :
“Em que pese existir uma inevitável associação entre o estudo prévio de impacto ambiental e o meio ambiente natural, o EIA/RIMA não é um instrumento somente voltado a esse aspecto. Assim, é perfeitamente aplicável às demais «partições» do meio ambiente, a saber, meio ambiente artificial, cultural e do trabalho (...)".

Nota-se que os referidos estudos agem como "elemento de restrição da discricionariedade que ele mesmo criou, porquanto permite à Administração, como base nos elementos do estudo, a concessão ou não da licença" ${ }^{19}$.

Havia até a edição da Lei Complementar n. 140/2011 o entendimento assente na doutrina de que a Resolução n. 237/97 do Conselho Nacional do Meio Ambiente (CONAMA) trazia, no seu anexo n. 1, rol de empreendimentos e atividades que estariam sujeitas ao licenciamento ambiental, sendo que o referido rol não era exaustivo, pois outros empreendimentos e atividades poderiam ser objeto do referido

\footnotetext{
${ }^{16} \mathrm{O}$ grifo é noso.

${ }^{17}$ SILVA, José Afonso. Direito ambiental constitucional cit.. p. 286.

${ }^{18}$ FIORILLO, Celso Antônio Pacheco. Curso de direito ambiental brasileiro cit.. p. 103.

${ }^{19}$ FIORILLO, Celso Antônio Pacheco. Curso de direito ambiental brasileiro cit.. p. 93.
} 
licenciamento, sendo que o fato de saber se ele era ou não causador de significativa degradação do meio ambiente era competência discricionária e exclusiva do órgão ambiental competente ${ }^{20}$.

Sobreveio a Lei Complementar n. 140/2011 não fazendo nenhuma referência a Resolução n. 237/97 do Conselho Nacional do Meio Ambiente (CONAMA), nem ao seu anexo n. 1, podendo-se, assim, manter o entendimento de que se trata de rol aplicável de forma exemplificativa, pois a Constituição não prevê qualquer limitação aos casos de Estudo de Impacto Ambiental ${ }^{21}$.

\title{
3. Da Unicidade de Licenciamento Ambiental
}

Verificada, por conseguinte, a necessidade de se obter a referida autorização, analisarse-á as regras de competência dos órgãos ambientais, como anteriormente declinado, pois essa competência material é comum a todos os entes federativos.

A Lei 6.938/81 previa, indiretamente, a possibilidade de haver mais de um licenciamento para o mesmo empreendimento, afirmando expressamente que o IBAMA teria uma atuação supletiva, verbis:

\begin{abstract}
“A construção, instalação, ampliação e funcionamento de estabelecimentos e atividades utilizadoras de recursos ambientais, considerados efetiva e potencialmente poluidores, bem como os capazes, sob qualquer forma, de causar degradação ambiental, dependerão de prévio licenciamento de órgão estadual competente, integrante do Sistema Nacional do Meio Ambiente - SISNAMA, e do Instituto Brasileiro do Meio Ambiente e Recursos Naturais Renováveis - IBAMA, em caráter supletivo, sem prejuízo de outras licenças exigíveis (art. 10; redação dada pela Lei $\mathrm{n}^{\mathrm{o}} 7.804$, de 18.07.89),22.
\end{abstract}

A doutrina também admitia essa possibilidade, conforme cita Paulo Affonso Leme Machado ${ }^{23}$ :

"Existirão atividades e obras que terão importância ao mesmo tempo para a Nação e para o Estado, e nesse caso, poderá haver duplicidade de licenciamento. O

\footnotetext{
${ }^{20}$ MUKAI, Toshio. Direito ambiental sistematizado cit.. p. 93.

${ }^{21}$ SILVA, José Afonso. Direito ambiental constitucional cit.. p. 291.

${ }^{22} \mathrm{O}$ grifo é noso.

${ }^{23}$ MACHADO, Paulo Affonso Leme. Direito ambiental brasileiro. 12 ed. São Paulo: Malheiros, 2004. p. 262.
} 
deferimento ou indeferimento do licenciamento deverão ser respeitados, aplicandose, inclusive, as sanções de cada legislação - federal, estadual, ou municipal, em caso de desobediência".

O fato de haver duas ou mais licenças para o mesmo empreendimento foi admitida pela Superior Tribunal de Justiça ${ }^{24}$, inclusive.

Sucede, no entanto, que a Lei Complementar n. 140/2011 expressamente vedou a possibilidade de haver duplicidade de licenciamento, conforme dispõe o art. 13:

"Os empreendimentos e atividades são licenciados ou autorizados, ambientalmente, por um único ente federativo, em conformidade com as atribuições estabelecidas nos termos desta Lei Complementar.

\section{$\S 1^{\circ}$ Os demais entes federativos interessados podem manifestar-se ao} órgão responsável pela licença ou autorização, de maneira não vinculante, respeitados os prazos e procedimentos do licenciamento ambiental.

$\S 2^{\circ}$ A supressão de vegetação decorrente de licenciamentos ambientais é autorizada pelo ente federativo licenciador.

$\S 3^{\circ}$ Os valores alusivos às taxas de licenciamento ambiental e outros serviços afins devem guardar relação de proporcionalidade com o custo e a complexidade do serviço prestado pelo ente federativo" ${ }^{, 25}$.

\footnotetext{
${ }^{24}$ Transcreve-se, a propósito: "ADMINISTRATIVO E AMBIENTAL. AÇÃO CIVIL PÚBLICA. DESASSOREAMENTO DO RIO ITAJAÍ-AÇU. LICENCIAMENTO. COMPETÊNCIA DO IBAMA. INTERESSE NACIONAL. 1. Existem atividades e obras que terão importância ao mesmo tempo para a Nação e para os Estados e, nesse caso, pode até haver duplicidade de licenciamento. 2. O confronto entre o direito ao desenvolvimento e os princípios do direito ambiental deve receber solução em prol do último, haja vista a finalidade que este tem de preservar a qualidade da vida humana na face da terra. $O$ seu objetivo central é proteger patrimônio pertencente às presentes e futuras gerações. 3. Não merece relevo a discussão sobre ser o Rio Itajaí-Açu estadual ou federal. A conservação do meio ambiente não se prende a situações geográficas ou referências históricas, extrapolando os limites impostos pelo homem. A natureza desconhece fronteiras políticas. Os bens ambientais são transnacionais. A preocupação que motiva a presente causa não é unicamente o rio, mas, principalmente, o mar territorial afetado. O impacto será considerável sobre o ecossistema marinho, o qual receberá milhões de toneladas de detritos. 4. Está diretamente afetada pelas obras de dragagem do Rio Itajaí-Açu toda a zona costeira e o mar territorial, impondo-se a participação do IBAMA e a necessidade de prévios EIA/RIMA. A atividade do órgão estadual, in casu, a FATMA, é supletiva. Somente o estudo e o acompanhamento aprofundado da questão, através dos órgãos ambientais públicos e privados, poderá aferir quais os contornos do impacto causado pelas dragagens no rio, pelo depósito dos detritos no mar, bem como, sobre as correntes marítimas, sobre a orla litorânea, sobre os mangues, sobre as praias, e, enfim, sobre o homem que vive e depende do rio, do mar e do mangue nessa região." BRASIL. Superior Tribunal de Justiça. Recurso Especial $n^{\circ}$ 588.022-SC, rel. Min. José Delgado, in DJU do dia 05.04.2004, Disponível em: $<$ www.stj.jus.br>. Acesso em 24 nov. 2011.
} 
A novel norma tenta extirpar o sistema da dualidade de licenças, bem como a possibilidade de direcionamento à órgãos ambientais não capacitados, tanto que a própria lei veda a realização de convênio entre os entes federativos se o ente delegado não disponha de órgão ambiental capacitado ${ }^{26}$, conceituando-o ${ }^{27}$, inclusive.

Ressalte-se, contudo, que a lei não extinguiu o sistema de supletividade dos entes federativos de atuar na questão ambiental, mas se o fizerem o farão por inexistência de órgão ambiental capacitado, reafirmando o sistema único de licenciamento e suprimindo a supletividade abstrata do Instituto Brasileiro do Meio Ambiente e Recursos Naturais Renováveis (IBAMA) ${ }^{28}$.

\section{Do Procedimento Administrativo Público}

A competência de licenciamento ambiental está disciplinada nos artigos $7^{\circ}, 8^{\circ}$ e $9^{\circ}$ da Lei Complementar n. 140/2011, que nos apresenta as ações administrativas da União, dos Estados e dos Municípios, respectivamente. Lembrando que o Distrito Federal cumula as atribuições dos Estados e Municípios, conforme expressa disposição legal ${ }^{29}$.

O empreendedor ao requerer a licença ambiental deverá elaborar estudos, que serão realizados por equipe multidisciplinar habilitada, com coleta e aquisição dos dados e informações, trabalhos e inspeções de campo, análise de laboratório, estudos técnicos e

\footnotetext{
${ }^{25} \mathrm{O}$ grifo é noso.

${ }^{26}$ Lei Complementar n. 140/2011, caput, art. $5^{\circ}$ "O ente federativo poderá delegar, mediante convênio, a execução de ações administrativas a ele atribuídas nesta Lei Complementar, desde que o ente destinatário da delegação disponha de órgão ambiental capacitado a executar as ações administrativas a serem delegadas e de conselho de meio ambiente".

${ }^{27}$ Lei Complementar n. 140/2011, parágrafo único, art. $5^{\circ}$ “Considera-se órgão ambiental capacitado, para os efeitos do disposto no caput, aquele que possui técnicos próprios ou em consórcio, devidamente habilitados e em número compatível com a demanda das ações administrativas a serem delegadas".

${ }^{28}$ A Lei Complementar n. 140/2011 em seu art. 21 revogou os $\S \S 2^{\circ}, 3^{\circ}$ e $4^{\circ}$ do art. 10 e o $\S 1^{\circ}$ do art. 11 da Lei 6.938/81, sendo que o seu art. 20 deu nova redação ao art. 10, caput e ao seu $\S 1^{\circ}$ da Lei 6.938/81, verbis: "Art. 20. O art. 10 da Lei no 6.938, de 31 de agosto de 1981, passa a vigorar com a seguinte redação: "Art. 10. A construção, instalação, ampliação e funcionamento de estabelecimentos e atividades utilizadores de recursos ambientais, efetiva ou potencialmente poluidores ou capazes, sob qualquer forma, de causar degradação ambiental dependerão de prévio licenciamento ambiental. $\S 1^{\circ}$ Os pedidos de licenciamento, sua renovação e a respectiva concessão serão publicados no jornal oficial, bem como em periódico regional ou local de grande circulação, ou em meio eletrônico de comunicação mantido pelo órgão ambiental competente".

${ }^{29}$ Previsto no art. $10^{\circ}$ da Lei Complementar n. 140/2011.
} 
científicos, acompanhamento e monitoramento dos impactos, sendo que todas as despesas e custos serão suportados pelo titular da obra ou atividade ${ }^{30}$.

A equipe multidisciplinar não precisa ser independente do proponente do projeto, vez que a legislação assim não impõe ou traz vedações ${ }^{31}$, a bem da verdade apenas aduz que esta deverá ser paga pelo requerente e que se sujeita, juntamente com ele, às sanções administrativas, civis e penais ${ }^{32}$.

Os estudos confeccionados pela equipe multidisciplinar sob as expensas do empreendedor não podem ser considerados meramente privados, pois desde $\mathrm{o}$ nascedouro há intervenção dos órgãos públicos ambientais, podendo-se dizer que o estudo de impacto ambiental tem natureza jurídica de procedimento público ${ }^{33}$.

Dessa forma, o empreendedor definindo a competência do órgão ambiental capacitado e requerendo o seu licenciamento instaura-se um procedimento administrativo público, chamado de licenciamento ambiental para a obtenção das licenças previstas na Resolução 237/97 do Conselho Nacional do Meio Ambiente (CONAMA):
" $8^{\circ}$ - O Poder Público, no exercício de sua competência de controle, expedirá as seguintes licenças:
I - Licença Prévia (LP) - concedida na fase preliminar do planejamento do empreendimento ou atividade aprovando sua localização e concepção, atestando a viabilidade ambiental e estabelecendo os requisitos básicos e condicionantes a serem atendidos nas próximas fases de sua implementação;

II - Licença de Instalação (LI) - autoriza a instalação do empreendimento ou atividade de acordo com as especificações constantes dos planos, programas e projetos aprovados, incluindo as medidas de controle ambiental e demais condicionantes, da qual constituem motivo determinante;

III - Licença de Operação (LO) - autoriza a operação da atividade ou empreendimento, após a verificação do efetivo cumprimento do que consta das licenças anteriores, com as medidas de controle ambiental e condicionantes determinados para a operação.

\footnotetext{
${ }^{30}$ SILVA, José Afonso. Direito ambiental constituciona cit.. p. 286.

${ }^{31}$ FIORILlO, Celso Antônio Pacheco. Curso de direito ambiental brasileiro cit.. p. 99.

${ }^{32}$ Previsto no art. 11 da Resolução 237/97 do Conselho Nacional do Meio Ambiente (CONAMA).

${ }^{33}$ MACHADO, Paulo Affonso Leme. Direito ambiental brasileiro cit.. p. 208.
} 
Parágrafo único - As licenças ambientais poderão ser expedidas isolada ou sucessivamente, de acordo com a natureza, características e fase do empreendimento ou atividade".

Estas licenças não são suprimíveis, ou seja, não se dará licença de operação aquele que não tenha obtido licença de instalação e/ou prévia, seguindo-se o rito procedimental administrativo, que exige, ainda no início, a publicação ${ }^{34}$ do requerimento de licenciamento.

Note-se que esta vindicação é decorrência do princípio administrativo constitucional da informação, em que a população poderá acompanhar o procedimento de licenciamento ambiental desde a contratação da equipe multidisciplinar até as fases de comentários e de Audiências Públicas ${ }^{35}$, bem como quando da sua renovação e concessão, permitindose a realização do princípio da participação popular ${ }^{36}$.

Cita-se, a respeito, José Afonso da Silva ${ }^{37}$ :

"A participação popular no procedimento de estudo ambiental é uma exigência da natureza mesma do patrimônio ambiental. Se este é um bem de uso comum do povo, como diz o art. 225 da Constituição, nada mais coerente do que esse povo ter acesso a um instrumento da política de preservação, melhoria e recuperação da qualidade do meio ambiente".

Dessa forma, percebe-se que a participação popular será salutar na análise dos estudos ambientais tendentes ao licenciamento.

Vê-se, por conseguinte, que o requerente deve observar, para a obtenção das licenças anteriormente esposadas, o rito procedimental administrativo ambiental descrito na Resolução 237/97 do Conselho Nacional do Meio Ambiente (CONAMA):
"O procedimento de licenciamento ambiental obedecerá às seguintes etapas:
I - Definição pelo órgão ambiental competente, com a participação do empreendedor, dos documentos, projetos e estudos ambientais, necessários ao início do processo de licenciamento correspondente à licença a ser requerida;

\footnotetext{
${ }^{34}$ Previsto no art. 10, $\S 1^{\circ}$, da Lei 6.938/81 (Redação dada pela Lei Complementar 140/2011).

${ }^{35}$ MACHADO, Paulo Affonso Leme. Direito ambiental brasileiro cit.. p. 236.

${ }^{36}$ FIORILLO, Celso Antônio Pacheco. Curso de direito ambiental brasileiro cit.. p. 104.

${ }^{37}$ SILVA, José Afonso. Direito ambiental constitucional cit.. p. 299.
} 
II - Requerimento da licença ambiental pelo empreendedor, acompanhado dos documentos, projetos e estudos ambientais pertinentes, dando-se a devida publicidade;

III - Análise pelo órgão ambiental competente, integrante do SISNAMA ${ }^{38}$, dos documentos, projetos e estudos ambientais apresentados e a realização de vistorias técnicas, quando necessárias;

IV - Solicitação de esclarecimentos e complementações pelo órgão ambiental competente, integrante do SISNAMA, uma única vez, em decorrência da análise dos documentos, projetos e estudos ambientais apresentados, quando couber, podendo haver a reiteração da mesma solicitação caso os esclarecimentos e complementações não tenham sido satisfatórios;

V - Audiência pública, quando couber, de acordo com a regulamentação pertinente; VI - Solicitação de esclarecimentos e complementações pelo órgão ambiental competente, decorrentes de audiências públicas, quando couber, podendo haver reiteração da solicitação quando os esclarecimentos e complementações não tenham sido satisfatórios;

VII - Emissão de parecer técnico conclusivo e, quando couber, parecer jurídico;

VIII - Deferimento ou indeferimento do pedido de licença, dando-se a devida publicidade".

Tratando, por fim, da razoabilidade da duração do procedimento de licenciamento ambiental, vez que a Emenda Constitucional n. 45/2004 inseriu o inciso LXXVIII no art. $5^{\circ}$ da Constituição assegurando a todos, no âmbito judicial e administrativo, a razoável duração do processo.

Essa garantia constitucional é um conceito legal indeterminado, que deveria ser preenchida/declarada pelos magistrados ao apreciar os casos concretos ${ }^{39}$, ou seja, somente num controle jurisdicional que é sabidamente demorado por essência, não se fazendo cumprir o referido princípio constitucional.

\footnotetext{
${ }^{38}$ Sistema Nacional do Meio Ambiente (constituído pela Lei n. 6.938, de 31 de agosto de 1981).

${ }^{39}$ FIORILLO, Celso Antônio Pacheco. Curso de direito ambiental brasileiro cit.. p. 107.
} 
A lei, então, declina expressamente ${ }^{40}$ da necessidade dos órgãos públicos ambientais de observar os prazos de duração do licenciamento, que estão, ainda, previstos na Resolução 237/97 do Conselho Nacional do Meio Ambiente (CONAMA) ${ }^{41}$.

\section{CONSIDERAÇÕES FINAIS}

O regime das autorizações ambientais no Brasil foi investigada à luz da legislação, da doutrina e da jurisprudência pátria, num breve cotejo da novel regulamentação ambiental, isto é, da Lei Complementar n. 140 de 08 de dezembro de 2011.

Recordamos, inicialmente, da importância do estudo das competências no Brasil, vez que por expressa previsão constitucional, constante no art. 23 , há competência material comum da União, dos Estados, do Distrito Federal e dos Municípios, ou seja, todos podem, a priori, realizar licenciamentos ambientais no Brasil, gerando, assim, a grande controvérsia da duplicidade e, a contrario sensu, da unicidade de licenciamentos.

Note-se que, favoravelmente a tese da duplicidade, pesa a existência de posicionamento jurisdicional do Superior Tribunal de Justiça que é o órgão jurisdicional máximo infraconstitucional do Brasil.

Entendemos, no entanto, que os tribunais também deverão se curvar as novas regras, vez que a lei complementar inovando a sistemática anterior expressamente fez constar que a supletividade somente é aplicável aos casos de inexistência de órgãos ambientais capacitados e que aqueles que concorrerem no licenciamento somente o farão auxiliando o encarregado pelo licenciamento, ou seja, não poderá licenciar também, isto é: unicidade de licenciamento.

Outra grande controvérsia sobre o licenciamento ambiental decorreu da inserção constitucional da razoabilidade da duração do processo, tanto no âmbito judicial quanto administrativo, esculpida no inciso LXXVIII no art. $5^{\circ}$ da Constituição Federal, acrescentado pela Emenda Constitucional n. 45/2004.

Obtempera-se, então, que a novel lei trouxe previsão expressa de que os órgãos ambientais devem observar os prazos de duração do licenciamento, suspensão do prazo pelo requerimento de exigência complementares e prorrogação tácita das licenças

\footnotetext{
${ }^{40}$ Previsto no art. $14^{\circ}$ da Lei Complementar n. 140/2011.

${ }^{41}$ Previsto no art. 14 a 18 da Resolução n. 237/97 do Conselho Nacional do Meio Ambiente (CONAMA).
} 
enquanto não decididas pelo órgão ambiental sobre a renovação da referida licença, adequando-se, por fim, ao referido preceito constitucional.

Vislumbra-se, então, que a regulamentação das autorizações ambientais no Brasil sofreu poucas, mas relevantes alterações no seu tratamento, positivando e esclarecendo questões práticas, que devido à atual proeminência do Estado Brasileiro no cenário mundial e do agigantamento da importância ambiental faz-se necessária e já se destaca pela sua efetividade, ressaltando-se dentre as milhares de leis do Brasil.

\section{REFERÊNCIAS}

ANTUNES, Paulo de Bessa. Direito ambiental. 8 ed. Rio de Janeiro: Lumen Juris, 2005 .

BAPTISTA, Rodrigo. Sarney critica excesso de leis no Brasil. Agência Senado, Brasília, 01 dez. 2010. Notícias. Disponível em: $<\mathrm{http}$ ://www.senado.gov.br/noticias/sarney-critica-excesso-de-leis-no-brasil.aspx $>$. Acesso em: 01 fev. 2012.

BASTOS, Celso Ribeiro. Curso de direito constitucional. 22 ed. São Paulo: Malheiros, 2010 .

CONSELHO NACIONAL DO MEIO AMBIENTE. Resolução 237 de 19 de dezembro de 1997. Disponível em: <http://www.mma.gov.br>. Acesso em: 24 nov. 2011.

SUPREMO TRIBUNAL FEDERAL. Ação direita de inconstitucionalidade $n^{\circ} 1.086$, rel. Min. Ilmar Galvão, in DJU do dia 07-06-2001, Disponível em: <www.stf.jus.br>. Acesso em: 01 fev. 2012.

CUNHA JÚNIOR, Dirley da. Curso de direito administrativo. 7 ed. $2^{\text {a }}$ tirag. Salvador: Editora Juspodivm, 2008.

FIORILlO, Celso Antônio Pacheco. Curso de direito ambiental brasileiro. 9 ed. São Paulo: Saraiva, 2008.

MACHADO, Paulo Affonso Leme. Direito ambiental brasileiro. 12 ed. São Paulo: Malheiros, 2004.

MUKAI, Toshio. Direito ambiental sistematizado. 5 ed. Rio de Janeiro: Forense Universitária, 2005. 
SILVA, José Afonso. Direito ambiental constitucional. 6 ed. São Paulo: Malheiros, 2007. 